\title{
Is diet an essential risk factor for coronary heart disease?
}

\author{
K. P. BALL \\ M.D., F.R.C.P. \\ Department of Community Medicine, Central Middlesex Hospital, London NW10 7NS
}

\begin{abstract}
Summary
Cigarette smoking, hypertension and diet each play a major role in the development of coronary heart attacks in most industrialized nations. In some countries where cigarette smoking and hypertension are prevalent there is a low risk of coronary heart disease (CHD). Hyperlipidaemia resulting from national food habits appears to be the essential factor in the high rates of CHD in developed countries.
\end{abstract}

\section{Introduction}

Cigarette smoking, hypertension and diet are recognized as the main risk factors for coronary heart disease (CHD). Certainly in developed countries they are all important and are both additive and cumulative (Fig. 1). Evidence is presented to show that diet is the only essential and fundamental factor. Cigarette smoking by itself doubles the chances of a coronary attack. A combination of hypertension ( $>160 / 90 \mathrm{mmHg}$ ) or raised cholesterol levels ( $>6.5 \mathrm{mmol} / \mathrm{l}$ ) quadruples the hazard. When all three factors coincide the risk increases more than 8-fold. But in some countries certain of these factors commonly occur yet, at any rate until recently, coronary disease has been rare. These include Greece, Yugoslavia, Italy, Spain and Portugal which are all South European countries; but the nation which is of outstanding interest in this context is Japan.

\section{Cigarette smoking}

In northern European countries and particularly in the U.K. cigarette smoking is a strong and the most clearly defined factor leading to CHD. The risk of a fatal attack for cigarette smokers is 2 to 3 times greater than for non-smokers. But heavy smokers under the age of 45 have 10 to 15 times the risk (Fig. 2). Some, but not all, studies have shown that sudden death is more frequent in heavy smokers and that it is likely to occur many years earlier than in non-smokers. The effect of stopping smoking provides the strongest evidence. Within 5 years, otherwise healthy doctors under the age of 55 years had halved their risk of a fatal heart attack (Fig. 3) (Doll and Peto, 1976). A Swedish study also showed

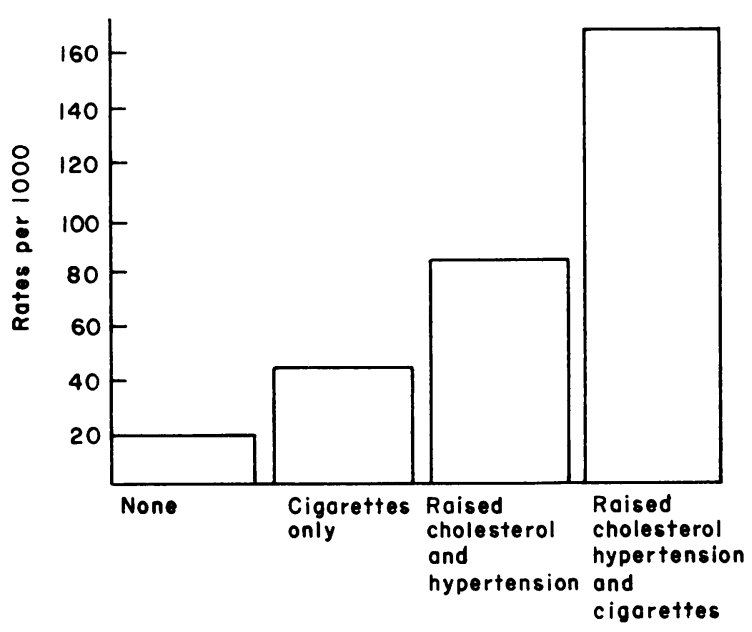

FIG. 1. Additive effect of cigarettes, raised cholesterol and hypertension on the incidence of a first major coronary event. (From Inter Society Commission for Heart Disease Resources, Circulation, 1970).

that patients who stopped smoking after a coronary attack halved their risk of either fatal or non-fatal relapse (Wilhemsson et al., 1975) (Fig. 4).

Yet in Japan heavy cigarette smoking rarely leads to CHD (Fig. 5).

\section{Hypertension}

Raised BP is well recognized as an important predictor of CHD (Fig. 6). This fact is known to insurance companies (Metropolitan Life Insurance, 1961). A man aged 35 years with a BP of $150 / 100$ $\mathrm{mmHg}$ has an average loss of life expectancy of 16.5 years compared with one whose blood pressure is normal and this risk is more due to CHD than to stroke. Mild degrees are responsible for many more cases of CHD than the few cases of severe hypertension. The incidence of fatal stroke both in the U.K. and America has been falling for many years, probably owing to the effects of lower salt consumption, with wider use of food refrigeration, 


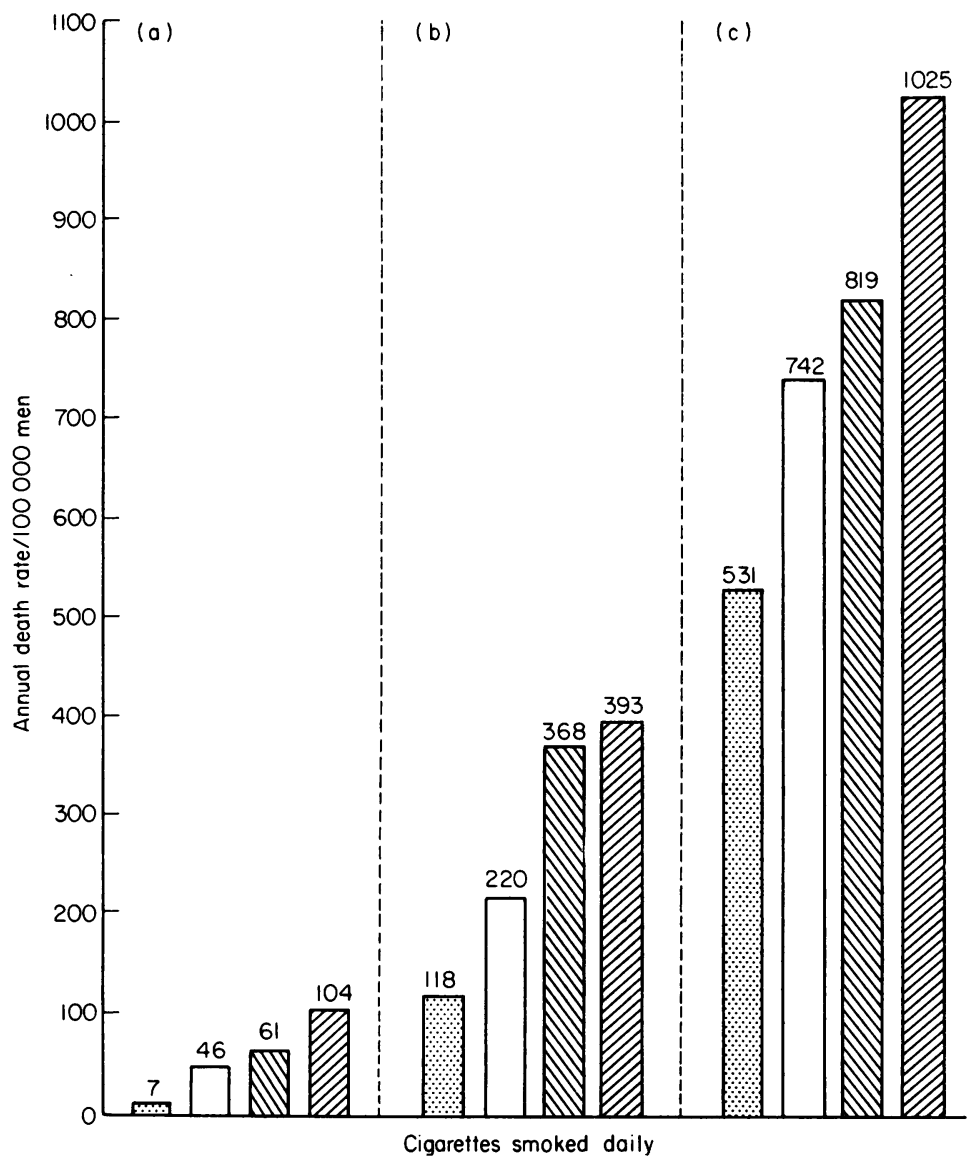

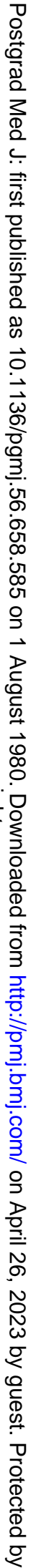

FIG. 2. U.K. Study of mortality from CHD in male non-smokers and current smokers by age and smoking category. (a) Age under 45 years, (b) age 45-54 years, (c) age 55-64 years. $:=0, \square=1-14, \mathbb{N}=15-24, \mathbb{Z}=25+$ cigarettes daily.

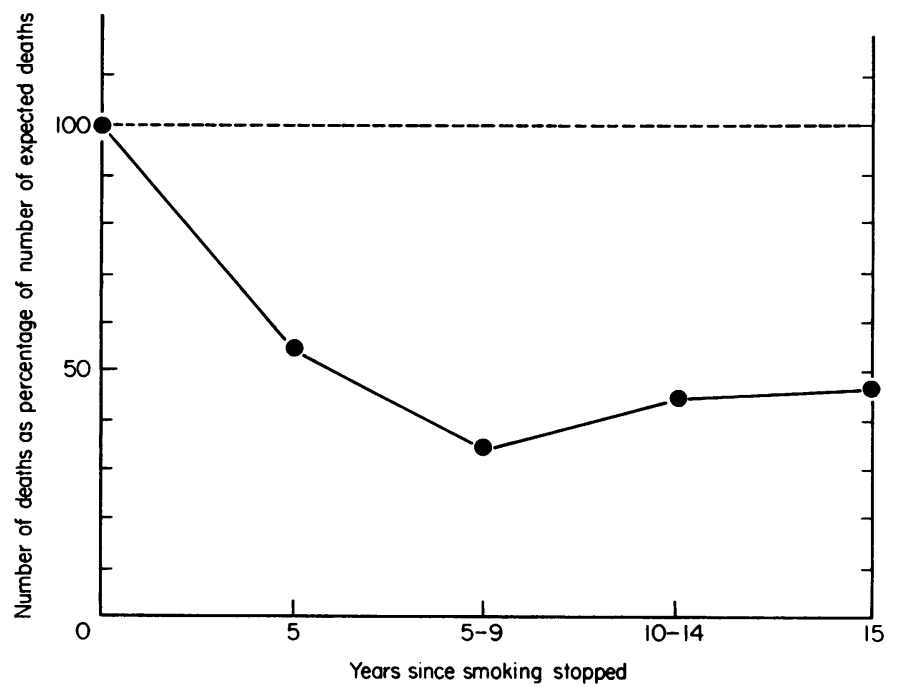

Fig. 3. Coronary heart disease mortality in ex-cigarette smokers $(-0)$ by number of years stopped smoking compared with mortality in continuing smokers (-- ) men aged 30-54 years. After Doll and Peto, 1976. 
but also to drug therapy. This encouraging reduction of hypertensive disease may be one cause of the falling CHD mortality in the U.S.A. and Australia, and a flattening out of the rate in the U.K. Yet in Japan, with the highest recorded stroke mortality in the world, CHD is uncommon (Fig. 7).

\section{Diabetes}

In the West, arterial disease is the most important

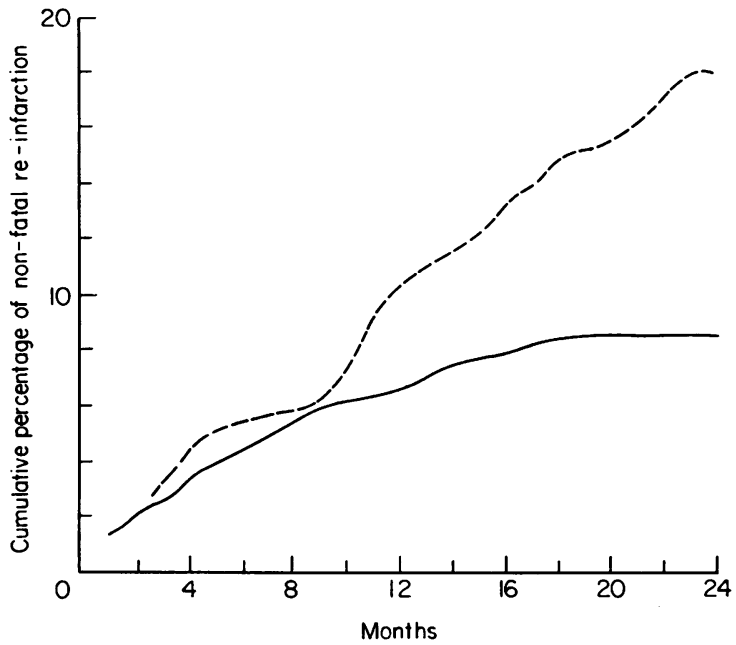

Fig. 4. Cumulative percentage of non-fatal relapse following infarction in $\mathbf{4 0 5}$ patients. Those continuing smoking ( $--n=174,43 \%)$ compared with those who stopped $(-n=231,57 \%)$. Redrawn from Wihelmsson et al. 1975. cause of disability and death amongst diabetics. Yet there is little evidence that current methods of treatment have reduced the toll of diabetic atherosclerosis. A comparison between American and Japanese diabetic diets shows that the Americans tend to have a much higher percentage of calories from fat (Table 1) (Thomas, 1979). Could this high

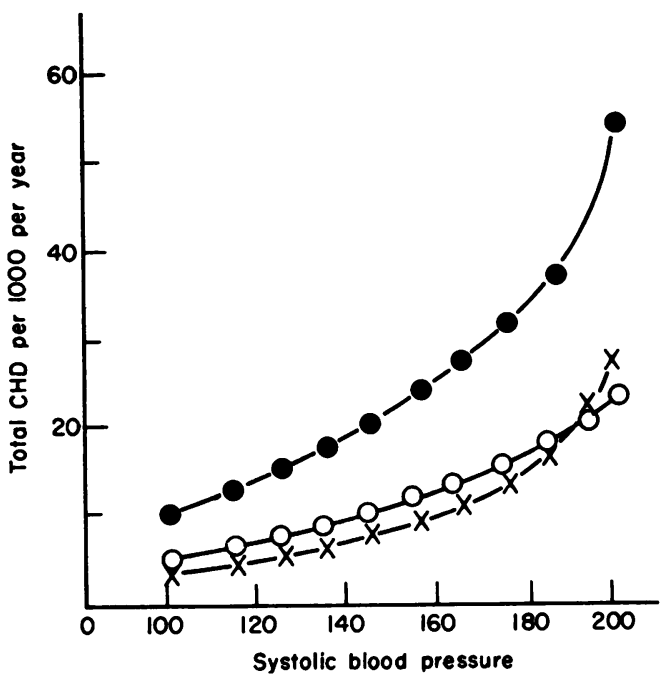

FIG. 6. CHD incidence (averaged over a 16-year period) in relation to blood pressure at initial examination. From Journal of the Royal College of Physicians, 1976 with kind permission of the Editor. - male 55-64 years, $0-0$ male $45-54$ years, $x-x$ female 55-64 years.

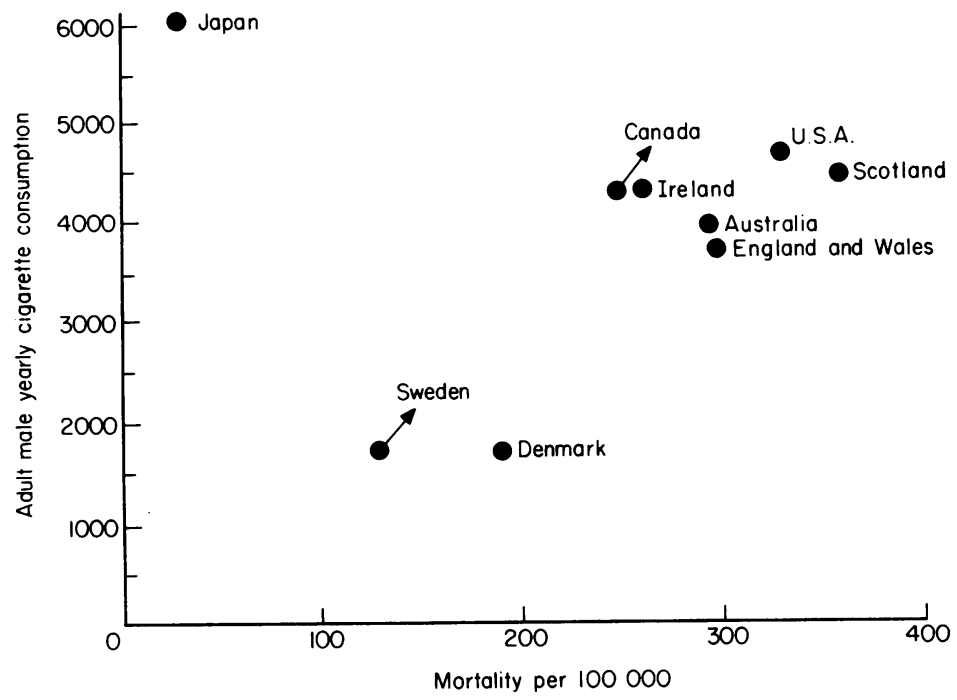

FIG. 5. Mortality per 100000 for ischaemic heart disease (A830) amongst men aged 45-54 years and male yearly cigarette consumption. 
mortality rate be due to the way we treat our diabetics? Emphasis is placed on glucose levels in blood and urine rather than on abnormal plasma lipids which are more likely to be associated with arterial disease. Truswell, Thomas and Brown (1975) found that while in $70 \%$ of diabetic clinics blood glucose was estimated routinely, in only $25 \%$ was plasma cholesterol recorded. Only 8 to $9 \%$ of them restricted dietary fat as routine.

The outlook for a diabetic after a heart attack is particularly poor and a recent study showed that $50 \%$ of the 28 patients admitted to hospital for an acute myocardial infarction were dead after one year.

But in Japan, arterial disease is a rare complication of diabetes.

Why does Japan have such a low overall incidence of CHD?

Japanese men have the highest recorded rate of cigarette consumption in the world, although few of their women smoke (Todd, 1978). There is a good correlation between the incidence of fatal CHD in men and their cigarette consumption in those countries where this consumption is known, except for Japan (Fig. 5). Likewise, there is a good correla-

Table 1. Calorie ( $\%$ ) distribution in American and Japanese diabetic diets

\begin{tabular}{lcc}
\hline & U.S.A. & Japan \\
\hline Carbohydrate & 40 & 60 \\
Protein & 15 & 15 \\
Fat & 45 & 25 \\
\hline
\end{tabular}

tion between mortality rate for stroke and CHD in middle-aged men for the same countries, again with the exception of Japan (Fig. 7).

In the U.S.A. diabetics are 8 times more likely to die of coronary attacks than they are in Japan

TABLE 2. Mortality rates (\%) from arterial and renovascular disease among American and Japanese diabetics

\begin{tabular}{lcr}
\hline & U.S.A. & Japan \\
\hline Coronary & 53.3 & 6.5 \\
Cerebral & 12.4 & 11.1 \\
Gangrene & 1.3 & 0.3 \\
Renovascular & 9.2 & 19.3 \\
\hline
\end{tabular}

(Table 2). How can it be that in an industrial country whose men smoke heavily, where hypertension and strokes are rife and where environmental stress is high, coronary disease is rare? This is one of the most productive questions that has been asked, and to answer it epidemiologists have undertaken valuable studies.

In 1965 a large study was started comparing mert in Japan with those of Japanese ancestry who had migrated to Hawaii or California (Kato et al. 1973)*. In Japan men were found to be lighter; shorter and have thinner skin folds than in the 2

* Figures 8-9 are redrawn from this article by kind permission of the editor of' American Journal of Epidemiology.

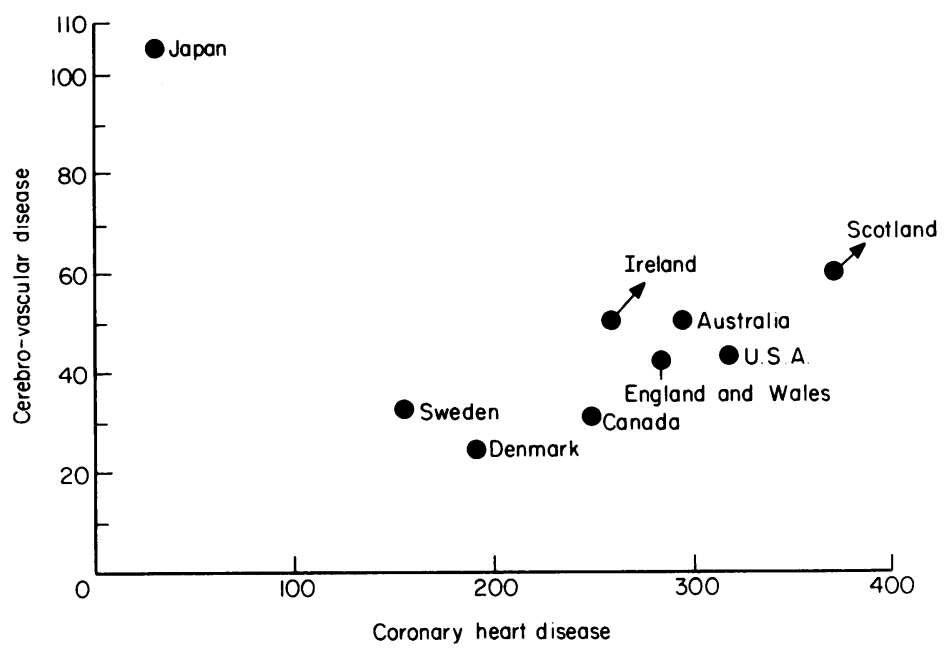

Fig. 7. Death rate per 100000 from cerebro-vascular disease and CHD amongst men aged 45-54 years in 9 countries (WHO 1973). 
migrant groups. They ate less fat and less of this was saturated (Fig. 8). They consumed much more complex unrefined carbohydrates (Fig. 9) and their plasma cholesterol levels were significantly lower (Fig. 10). More importantly, the mortality rates for CHD in Japan were significantly lower than those in Hawaii and California (Fig. 11).

Thus, in Japan, a country with a low intake of fat and a high intake of unrefined carbohydrate and vegetables, the risk of CHD is low even in the presence of cigarette smoking, high BP and diabetes. This strongly supports the hypothesis that dietaryinduced hyperlipidaemia is the fundamental factor in the production of CHD.

What might be the effect on people in this country should we change to such a diet or even to the traditional diets of the Mediterranean where the risk of CHD is also low? Would we merely replace CHD with strokes and cancer? The recent clofibrate trial (Oliver et al., 1978) raises the possibility that rapid excretion of cholesterol and bile salts might increase the risk of gall stones and alimentary cancer. It is of course possible that where high fat diets have been consumed over many years, the cholesterol-lowering regime, be it diet or drugs, might lead to a rapid outpouring of bile salts which could stimulate alimentary cancer. This might be favoured by delayed gut transit time in the presence
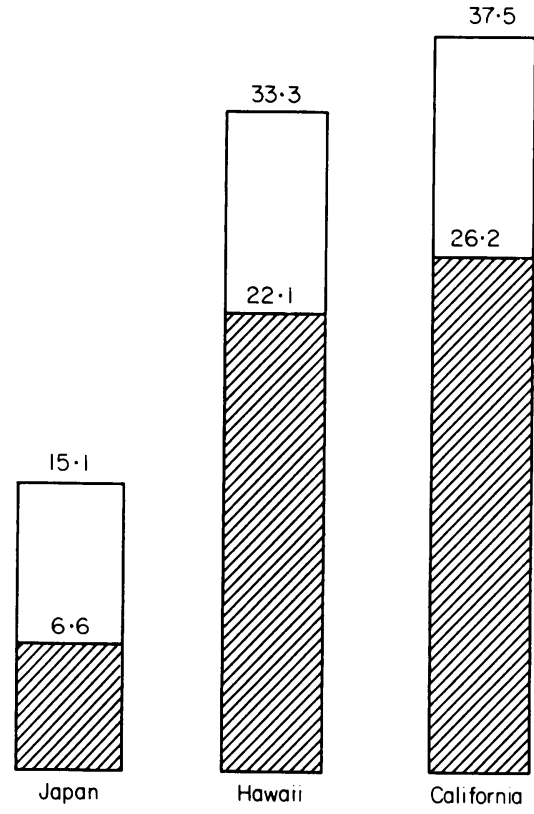

Percentage of calories consumed as total fat in Japanese men aged 45-69 years

Fig. 8. $\mathbb{Z}=$ Percentage of saturated fat. of a low fibre diet. Even if this were found to be so it would only be a further reason to prevent the development of dietary-induced hyperlipidaemia in the first place, starting in childhood thus avoiding overloading the body with lipids.

There is no evidence that a polyunsaturated fat diet increases the risk of cancer. The initial suggestion by the Los Angeles Study (Dayton et al., 1968) was fully answered by Ederer et al. (1971) who pooled results from 5 large intervention studies. The incidence of cancer was, if anything, lower in the patients treated with polyunsaturated fats.

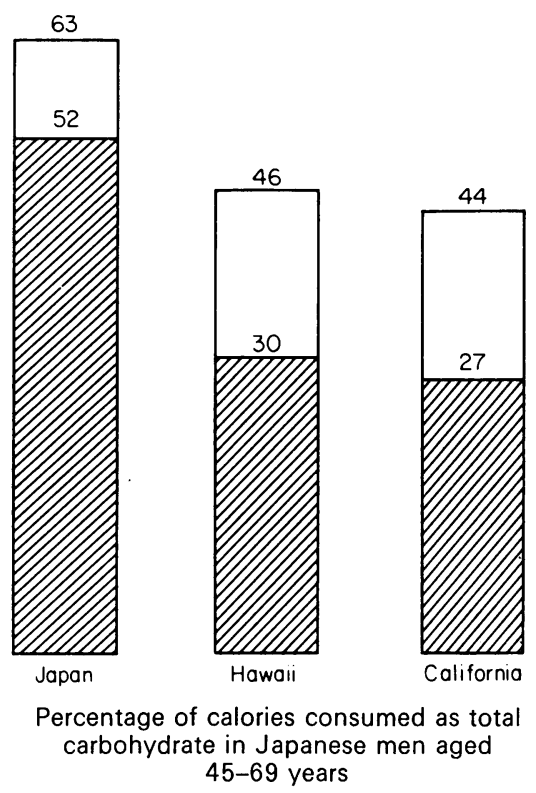

FIG. 9. $\mathbb{Z}=$ Percentage of complex carbohydrate.
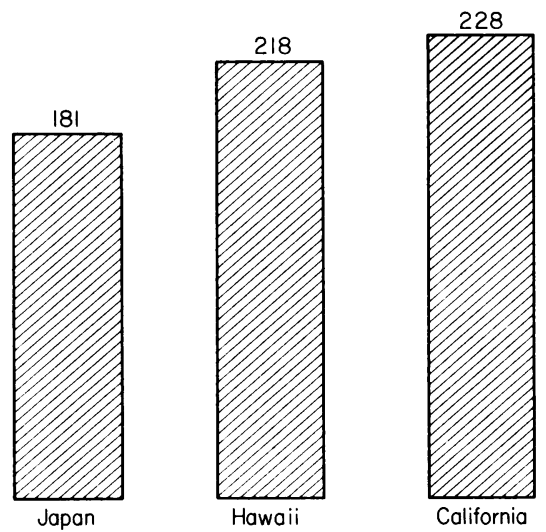

Fig. 10 Mean serum cholesterol in Japanese men aged 45-69 years. 
There is, in fact, growing evidence that diets high in saturated fats may actually increase the risk of carcinoma of the breast, the colon, and the pancreas.

\section{Dietary factors and cancer \\ Breast cancer}

Nulliparity and delayed age at first pregnancy have been shown to be associated with an increased risk of breast cancer. These factors cannot account for differences in the U.S./Japanese migrants to the United States or the current increase in breast cancer in Japan itself (Hirayama, 1978). It has been suggested that high fat diets could be a factor (Wynder and Hirayama, 1977), and animal studies have shown that such diets increase the risk of breast cancer in rats possibly owing to increased prolactin production. High prolactin levels have been recorded in women taking high fat Western diets compared with those taking low fat vegetarian diets (Hill and Wynder, 1976). A case control Canadian study of patients with breast cancer concluded that in these patients there was an association with total dietary fat (Miller et al., 1978). Wynder et al. (1976) concluded that 'since a high fat diet stimulates breast cancer development and circulating prolactin levels in animal models and is also typical of the diet of Western women, it may be reasonable to assume that high fat intake may exert its effect on breast cancer development by way of the endocrine system'.

\section{Cancer of the colon}

The incidence of carcinoma of the colon varies widely in different parts of the world. In Connecticut, U.S.A. the incidence is $\mathbf{3 0}$ times greater than in Nigeria (Doll, 1977). Although cancer of the colon is one of the commonest cancers in the U.S.A., the incidence in Japan is low. Dietary comparisons

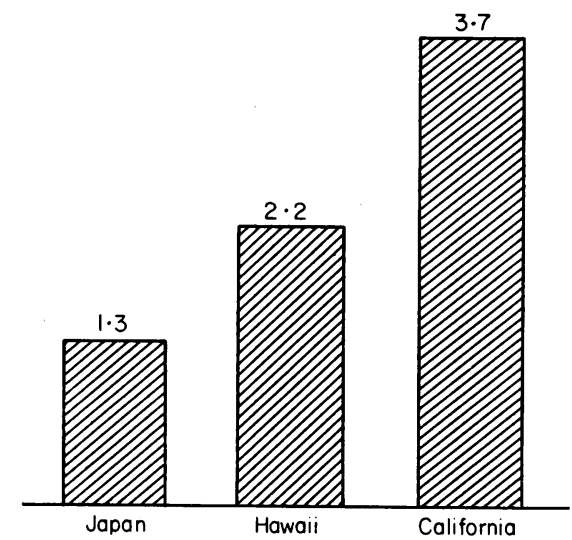

Fig. 11. Average annual mortality rate from $\mathrm{CHD} / 1000$ men aged 50-64 years. in different parts of the world have suggested that those high in fat and cholesterol and low in fibre are especially suspect. In the U.S.A. daily fat intake was found to be $152 \mathrm{~g}$ compared with $46 \mathrm{~g}$ in Japan. Dietary cholesterol intake was $556 \mathrm{mg} /$ day compared with $304 \mathrm{mg} /$ day in Japan (Weisburger et al., 1980). Evidence that the racial differences are environmental rather than genetic is supported by studies on migrants which have shown that Japanese migrants to the U.S.A. have high incidence rates of colon cancer. Case control studies in Japan have suggested that Japanese on a high fat Western diet have higher risks of colon cancer than Japanese on a low fat oriental diet. Furthermore, rates for colon cancer have increased in Japan in line with changes to a Western type diet since World War II (Wynder, 1979).

It has been suggested that total bile acids and neutral sterols found in the stools of those taking high fat diets may act as tumour promoters (Fig. 12). The effect may be greater where low fibre diets lead to small stools with less dilution of bile acids and longer gut transit time.

\section{Potential for improvement}

One of the most encouraging developments in recent years has been the fall in death rates fror

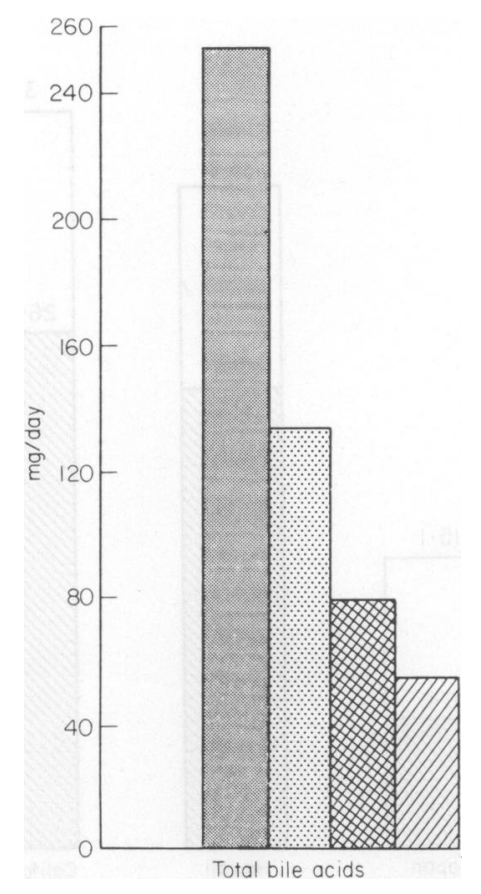

FIG. 12. Daily faecal bile acid excretion of various population groups. Americans, $⿴ 囗 0$ American vegetarians, Japanese, $\mathbb{Z}$ Chinese. 
CHD, not only in the U.S.A. but also in Australia, Canada, Finland and Belgium. Between 1969 and 1977 the mortality for ischaemic heart and related diseases in the U.S.A. fell by $19.5 \%$ in white men and $24 \%$ in white women. At the ages of 35-39 years, the fall was even greater, being $32 \%$ for white men and $36.5 \%$ for white women (Statistical Bulletin, 1979). Reporting these findings, the Metropolitan Life Insurance Company found it difficulty to assess the reason but stated 'In particular the health education campaigns of recent years have played a large part in public awareness of known risk factors in cardiovascular disease (such as hypertension, smoking, high cholesterol) and may be credited with the trend towards greater moderation in living habits'. That there have been substantial changes in risk factors in the U.S.A. is supported by the finding of the Framingham Offspring Study (Kannel et al., 1979). In this, the fathers in 1948 to 1950 at the age of 35-39 years were compared with sons of the same age in 1971-1975. The sons were found to have systolic BPs lower by $6.5 \mathrm{mmHg}$, serum cholesterol level lower by $0.22 \mathrm{mmol} / \mathrm{l}$, while the percentage of cigarette smokers had fallen from $75 \%$ in the fathers to $39 \%$ in the sons.

Trends in the U.K. have been less favourable with a rising incidence of CHD in the 1950s and 1960s especially in younger men. This has now been checked and there may even have been a slight fall (Florey, Melia and Darby, 1978). Nevertheless the U.K. compares badly with other countries in which rates have been falling. In 1968 the coronary mortality in men of $45-54$ years was $41 \%$ higher amongst U.S.A. white men than in men in England and Wales. By 1977 the U.S.A. rate had fallen below that of the U.K. We cannot be sure that the health education campaigns conducted, especially by the heart foundations in those countries, but not by those of the U.K., have been a major cause of their improved health record compared with ours. But it certainly suggests that their efforts may have been an important factor. The current policy of waiting for proof which cannot be obtained, before taking action on the prevention of coronary heart disease will surely be strongly criticized by future generations.

Dietary modification along the lines of the consensus of international opinion combined with a reduction of cigarette smoking and an encouragement for young and old to increase physical activity could bring a significant reduction in coronary mortality within 10 years.

\section{Conclusions}

Since risk factors are additive, the presence of any one should certainly lead to advice on controlling others. The newly detected hypertensive patient may need advice to stop smoking and lose weight before anti-hypertensive drugs are prescribed. The diabetic, apart from controlling his disease may need to take more exercise and stop smoking. The smoker who cannot stop should be helped to control other risk factors. All should be advised to eat wisely along the lines suggested and have their lipids checked.

In the short term, control of cigarette smoking in the U.K. could rapidly reduce the incidence of CHD amongst the $40 \%$ of the population who smoke.

In the longer term only an overall dietary improvement is likely to reduce the amount of coronary and other arterial disease since diet is the fundamental factor. This will involve a reduction of total fats, especially saturated fats, a partial substitution with polyunsaturated fats and an increase of unrefined carbohydrate.

An imaginative campaign to modify these major risk factors should do more to reduce the toll of heart disease in this country than any expansion of medical or surgical services for the treatment of the developed disease. This will require not only the support of doctors, teachers and health educators but leadership from government.

\section{References}

Dayton, S., Pearce, M.L., Goldman, H., Harnish, A., Plotkin, D., Shickman, M., Winfield, M., Zager, A. \& Dixon, W. (1968) Controlled trial of a diet high in unsaturated fat for prevention of atherosclerotic complications. Lancet, ii, 1060.

DolL, R. (1977) The prevention of cancer. Journal of the Royal College of Physicians of London, 11, 125.

Doll, R. \& Peto, R. (1976) Mortality in relation to smoking: 20 years' observations on male British doctors. British Medical Journal, 2, 1525.

Ederer, F., Leren, P., Turpeinen, O. \& Frantz, I. (1971) Cancer among men on cholesterol-lowering diets. Lancet, ii, 203.

Florey, C. DU V., Melia, R.J.W. \& Darby, S.C. (1978) Changing mortality from ischaemic heart disease in Great Britain. British Medical Journal, 1, 635.

HiLl, P. \& WYNDER, E.L. (1976) Diet and prolactin release. Lancet, ii, 806.

HiraYama, T. (1978) Epidemiology of breast cancer with special reference to the role of diet. Preventive Medicine, 7, 173.

KanNel, W.B., Feinleib, M., McNamara, P.M., Garrison, R.J. \& CASTELLI, W.P. (1979) The Framingham Offspring Study. American Journal of Epidemiology, 110, 281.

Kato, H., Tillotson, J., Nichaman, M., Rhoads, G., Hamilton, H.B. (1973) Epidemiologic studies of CHD and stroke in Japanese men living in Japan, Hawaii and California. American Journal of Epidemiology, 97, 372.

Metropolitan Life INSURANCE CoMPANY (1961) Blood Pressure: Insurance Experience and its Implications. Metropolitan Life Insurance Company, New York.

Miller, A.B., Kelly, A., Chor, N.W., Matthews, V., Morgan, R.W., Munan, L., Burch, J.D., Feather, J., Howe, G.R. \& JAIN, M. (1978) A study of diet and breast cancer. American Journal of Epidemiology, 107, 6, 499. 
Oliver, M.S., Heady, J.A., Morris, J.N. \& CoOper, J. (1978) A co-operative trial in the primary prevention of ischaemic heart disease using clofibrate. Report from the committee of principal investigators. British Heart Journal, 40, 1069.

Statistical Bulletin (1979) Recent Trends in Mortality from Cardiovascular Disease. Metropolitan Life Insurance Company, New York.

Thomas, B. (1979) Trends in the dietary management of diabetes. Update, January, 153.

ToDD, G.F. (1978) Cigarette consumption per adult of each sex in various countries. Journal of Epidemiology and Community Health, 32, 289.

Truswell, A.S., Thomas, B.J. \& Brown, A.M. (1975) Survey of dietary policy and management in British diabetic clinics. British Medical Journal, 4, 7.

WEISBurger, J.H., REDDY, B.S., SPINGARN, N.E. \& WYNDER,
E.L. (1980) Current views on the mechanisms involved in the etiology of colorectal cancer. In: Progress in Cance Research (Ed. by Winawer, S.J., Sherlock, P. \& Schottenfeld, D.) (in press). Raven Press, New York.

Wilhelmsson, C., Vedin, J.A., Elmfeldt, D., Tibblin, G. \& Wilhelmsson, L. (1975) Smoking and myocardial infarction. Lancet, $\mathbf{i}, 415$.

WYNDER, E.L. (1979) Dietary habits and cancer epidemiology Cancer, 43, 5, 1955.

Wynder, E.L., MacCornack, F., Hill, P., Cohen, L.A., Chan, P.C. \& Weisburger, J.H. (1976) Nutrition and the $\infty$ etiology and prevention of breast cancer. Cancer Detection $\vec{O}$ and Prevention, 1, 293.

WyNDER, E.L. \& Hirayama, T. (1977) Comparative epidemiology of cancers of the United States and Japan. Preventive Medicine, 6, 567. 